\title{
Análise do conhecimento e das concepções sobre saúde oral de alunos de odontologia: avaliação por meio de mapas conceituais
}

\author{
A nalysis of dental students' knowledge \\ and concepts in oral health: evaluation \\ by concept maps
}

Miriam Struchiner 1

Alexandre RezendeVieira 2

Regina Maria Vieira Ricciardi 1

\footnotetext{
1 Laboratório de Tecnologias Cognitivas, Núcleo de Tecnologia Educacional para a Saúde, Centro de Ciências da Saúde, Universidade Federal do Rio de Janeiro. Av. Marechal Trompowski s/no, bloco A, sala 26 Cidade Universitária Ilha do Fundão,

Rio de Janeiro, $\mathrm{R}$ 21949-900, Brasil. mchiner@nutes.ufrj.br ricciardi@nutes.ufrj.br 2 Laboratório de Genética Humana, Departamento de Genética, Instituto de Biologia, Centro de Ciências da Saúde, Universidade Federal do Rio de Janeiro. Av. Marechal Trompowski s/no bloco A, sala 67, 20 andar Cidade Universitária, Ilha do Fundão, Rio deJaneiro, RJ 21949-900, Brasil. vieira@acd.ufrj.br
}

A bstract This study sought to analyze sen ior dental students' cognitive structure concerning the topic of "enamel", which is fundamentally important for understanding oral health, since it offers basi c scientific concepts for clinical and preventive practices and is the main subject of several courses during dentistry training. The strategy used to analyze students' cognitive structures was Novak's Concept Maps, based on Ausubel's Meaningful Learning theory. Analysi s of students' maps all owed for a study of students' cognitive structure and concepts concerning oral heal th. It also fostered a diagnosis of students' knowledge in several important aspects of scientific and professional training. The results highlighted the need for rethinking the teaching/ learning process in dentistry training.

Key words Health Education; Dental Health Education; Educational Measurement; Dental Students

Resumo O objetivo inicial deste trabalho foi apreender a estrutura cognitiva de alunos do último ano (sétimo período) do curso de graduação em odontologia da UFRJ em relação à temática do esmalte. Essa temática é de fundamental importância para a compreensão da saúde oral, na medi da em que oferece concei tos científicos importantes e fundamentais para o exercício da prática clínica e preventi va, bem como por ser objeto de estudo em vári as disciplinas ao longo do curso de Odontologia. Para a análise da estrutura cognitiva, utilizou-sea estratégi a de mapas conceituais proposta por Novak efundamentou-se na teoria da Aprendizagem Significativa, de Ausubel. A análise dos mapas el aborados pel os estudantes possi bi litou um estudo não só sobre a estrutura cognitiva e as concepções sobre saú de oral dos alunos, como também permi tiu um diagnóstico do conheci mento em diversos aspectos rel evantes à formação ci entífica e profissi onal, apontando para a necessi dade de se repensar o processo ensino-aprendizagem nos cursos deOdontologia.

Palavras-chave Educação em Saúde; Educação em Saúde Bucal; Avaliação Educaci onal; Estudantes de Odontologia 
Introdução

A saúde oral e a formação do odontólogo no Brasil

No Brasil, a partir dos anos 60, a educação médica aumentou significativamente em quantidade, com perdas relevantes da qualidade da formação (Silva, 1987). Essa expansão, que na prática duplicou o número de cursos de Medicina, não teve qualquer repercussão favorável no atendimento à saúde. Muitas escolas foram criadas sem dispor de recursos humanos e materiais suficientes (Jatene, 1987). A realidade da educação odontológica apresenta um paralelo com a educação médica. Assim como na Medicina, a queda na qualidade do ensino é refletida na qualidade dos dentistas formados, uma vez que o número de escolas de Odontologia no Brasil já ultrapassa cem!

Vári os movimentos surgiram para discutir uma reforma curricular visando aproximar mais o dentista, que assiste uma parte mínima da população que tem acesso ao consultório odontológico, da realidade nacional. Um desses movimentos, a Integração Docente-Assistencial (Rede IDA), foi definido como a estratégia de associação das práticas de ensino, pesquisa e assistência, transformando a educação dos profissionais de saúde em um meio efetivo de formar profissionais adequados ao seu ambiente de trabal ho (ABEM , 1983). Outro modelo que procurou dar conta dessas questões, em nível curricular, foi o Problem based-learning (Aprendizado baseado em problemas) que, valendose de problemas relacionados à saúde oral, incentiva o desenvolvimento, pelos alunos, de soluções (diagnósticos e intervenções) inseridas na realidade em que os casos são apresentados, integrando fenômenos e achados de diferentes campos de saber (Wil son, 1996).

Os aspectos técnico-científico-assistenciais das profissões de saúde, e especificamente da saúde oral, deveriam ser equilibrados dentro da prática do ensino, não havendo mais uma predominância ou uma preferência pela superespecialização técnica. O currículo deveria promover, portanto, uma aproximação entre os conceitos científicos básicos e a prática clínica e esta deveria valorizar a solução dos problemas da população, dentro de uma perspectiva realista.

Apesar de hoje o currículo de Odontologia estar desenhado para favorecer essas aproximações, sua aplicação ainda apresenta uma tendência para o distanciamento, com a perpetuação de uma valorização dos procedimentos técnicos, de forma total mente afastada das necessidades e da real idade da população, assim como dos conceitos básicos. Isso, provavelmente, é reflexo de como os estudantes compreendem a profissão odontológica desde o início do curso, reforçado pelo enfoque dado por muitos professores.

\section{Definição do problema}

Essa situação e outros aspectos relevantes à formação profissional foram constatados em estudo recente real izado com alunos do curso de Odontologia da Faculdade de Odontologia da Universidade Federal do Rio de Janeiro UFRJ. No início da disciplina de Odontopediatria, foi feita uma análise do conhecimento de uma turma de alunos do sétimo período sobre o tema esmalte, com o objetivo de introduzir de forma sistemática uma inovação no ensino e acompanhar a sua implantação.

A inovação consistiu em oferecer como mais um recurso de ensino-aprendizagem um sistema hipermídia com o título Esmalte: A Porta de Entrada do Dente (Struchiner, 1998), desenvolvido de forma a contribuir para mudanças qualitativas no ensino da Odontologia. Hipermídia é um sistema computadorizado que permite a construção e o acesso a informações organizadas de forma não linear. Consiste em blocos de informação (nós) sobre um determinado domínio, interligados por meio de palavras-chave (hotwords) no texto. Do ponto de vista de sua estrutura lógica, a hipermídia é uma rede semântica onde uma série de conceitos estão associados. O leitor/ usuário pode, assim, percorrer o conteúdo de acordo com suas opções e necessidades de rel acionar conceitos, selecionando as palavras-chave contidas no texto e construindo sua própria rede de conhecimentos sobre o conteúdo estudado (Jonassen, 1996; Kommers et al., 1996). O interessante sobre esse tipo de estrutura não linear e o seu principal desafio para o processo educativo é exatamente a possibilidade de os alunos percorrerem diferentes caminhos na aprendizagem, conforme as relações semânticas e associações mentais por eles construídas, permitindo também a aprendizagem por descoberta.

O tema esmalte foi selecionado por possibilitar explorar conceitos científicos fundamentais ao exercício de uma prática clínica sólida, isto é, conhecimentos importantes na prevenção e na solução de problemas de saúde oral, integrando os ciclos básico e clínico. Essa temática é apresentada aos alunos ao longo do curso de graduação em Odontologia da UFRJ, em disciplinas dispersas como Histologia e Embriologia no primeiro ano; Dentística, Pato- 
logia, Cirurgia e Radiologia no segundo; Dentística, Estomatologia e Odontologia Social e Preventiva no terceiro e Odontopediatria no quarto, além de experiências durante toda a prática da clínica do curso.

A estrutura hipermídia e a problemática do tema esmal te no âmbito do currícul o despertaram interesse para implementar inovações e analisar suas contribuições em diferentes aspectos envolvidos no processo educativo, inclusive no conhecimento dos estudantes.

Dessa forma, era necessário que o conhecimento dos alunos fosse avaliado previamente à introdução da inovação, no caso, o sistema Esmalte: A Porta de Entrada do Dente, e que a metodologia de avaliação fosse compatível com os pressupostos educativos que nortearam a proposta e a estrutura de conhecimento viabilizada pela hipermídia. Como a hipermídia enfatiza a interconectividade entre conceitos e a construção do conhecimento pelo estudante, optou-se pela elaboração de mapas conceituais (Novak \& Gowin, 1984; Novak, 1998) para aval iar o conhecimento de conceitos e suas inter-relações.

Esse método e a anál ise dos dados obtidos, cujo processo descreveremos a seguir, possibilitaram um diagnóstico do conhecimento dos al unos em di versos aspectos relevantes à sua formação científica e profissional.

\section{Metodologia}

Abordagem sobre aprendizagem e avaliação

A abordagem sobre apren dizagem que apóia o presente estudo e que orientou a definição do método de avaliação do conhecimento dos alunos fundamenta-se nos princípios básicos do construtivismo (Cunningham et al., 1993; Duffy \& Jonassen, 1993; Wilson, 1996) e, especialmente, na aprendizagem de conceitos e princípios de Ausubel et al. (1978).

O construtivismo tem como premissa fundamental a idéia de que o indivíduo é agente de seu próprio conhecimento. Isto é, ele constrói significad os e define o seu próprio sentido e representação da realidade de acordo com suas experiências e vivências em diferentes contextos. Essas representações, no entanto, estão constantemente abertas a mudanças e suas estruturas formam as bases sobre as quais novos conhecimentos são construídos (Bednar et al., 1992; Novak, 1998).

Esse enfoque distancia-se da idéia de que o conhecimento acumulado possa ser compreen- dido e compartilhado através da mera transmissão de informações e de uma visão linear e simplificada dos fenômenos envolvidos, como se suas manifestações fossem imperiosamente as mesmas, independentemente do contexto, isto é, das condições em que ocorrem. Além disso, essas abordagens tradicionais terminam por privilegiar os modelos de aprendizagem por memorização em vez dos de aprendizagem significativa, ou seja, aquela que se dá por meio da reorganização de conceitos e proposições na estrutura cognitiva dos alunos (Ausubel et al., 1978). Por outro lado, as metodologias de avaliação tendem a encorajar a aprendizagem por memorização, perpetuando um ciclo vicioso, no qual o aluno praticamente memoriza fatos e/ ou al goritmos de resolução de problemas, sem desenvolver a necessária conscientização sobre seu próprio conhecimento, estrutura conceitual e princípios relacionados ao domínio estudado. Nessa perspectiva, e com base na teoria da aprendizagem significativa de Ausubel, é que Novak \& Gowin (1984) propuseram a estratégia de mapas conceituais para avaliação da estrutura cognitiva dos alunos.

Segundo Ausubel et al. (1978), a aprendizagem significativa só é possível quando o aluno relaciona conscientemente a nova informação a algum aspecto relevante de sua estrutura de conhecimento, ou seja, a aprendizagem é construída com base no conhecimento prévio do aluno num processo de hierarquização (subsunção), diferenciação progressiva e reconciliação integradora. Nossa estrutura cognitiva é organizada hierarquicamente com os conceitos e princípios mais específicos subordinados aos mais gerais (níveis de hierarquia); os conceitos, por sua vez, passam por uma diferenciação progressiva na medida em que novos conhecimentos e experiências levam a um refinamento e maior especificidade de suas regularidades, possibilitando novas ligações com outros conceitos (ligações válidas). Já a reconciliação progressiva é caracterizada quando dois ou mais conceitos são reconhecidos como relacionados, formando novos princípios ou proposições (conexões cruzadas).

\section{População}

O estudo foi realizado com alunos do sétimo período do curso de graduação em Odontologia $(\mathrm{N}=38)$, na disciplina de Odontopediatria. Ao chegarem a esse período, os participantes já vêm tendo contato com a temática sobre esmalte desde o início do curso em diversas disciplinas, dentre as quais, Odontopediatria ofe- 
rece a oportunidade de uma visão integrada dos conceitos sobre esmalte. Esse grupo de alunos de graduação passou por um dos vestibulares mais difíceis e concorridos na relação candidato-vaga, sendo a maior parte oriunda de famílias de classe média e, por isso, sempre com as melhores oportunidades educacionais, tanto no ensino básico, como no secundário. É importante lembrar que tais alunos estão no último ano do curso, que se encerra após o oitavo período, e, portanto, estão próximos de iniciar suas atividades profissionais.

Instrumentos

\section{- Mapas conceituais}

O instrumento utilizado para avaliar o conhecimento estrutural dos alunos foi o mapa conceitual, que é a forma mais trabal hada na literatura para avaliar tal conhecimento (Novak \& Gowin, 1984; Jonassen et al., 1993a; Moreira \& Buchweitz, 1993). Cada aluno elaborou um mapa sobre a temática do esmal te representando a estrutura conceitual e suas inter-relações.

O conceito de conhecimento estrutural está relacionado às teorias de aprendizagem significativa (Novak \& Gowin, 1984). É a forma de conhecimento que descreve como os conceitos de um determinado domínio se inter-relacionam. Pode ser também definido como conhecimento conceitual que envolve a integração de um novo conhecimento em estruturas mentais complexas.

A maneira mais indicada para apreender essa forma de conhecimento é por meio de mapas conceituais, que descrevem visualmente as correl ações entre as idéias de uma pessoa a respeito de um determinado conhecimento, representando, assim, sua estrutura cognitiva.

Um mapa conceitual é formado por dois elementos básicos: balões ou nós e linhas. Os balões representam os conceitos. As linhas definem as relações (Iigações) entre conceitos. Os mapas conceituais representam as relações significativas entre conceitos na forma de proposições. Proposições são dois ou mais conceitos associados por uma palavra de ligação. Quando as proposições incluem conceitos em níveis diferentes, temos as relações cruzadas.

Na Figura 2, por exemplo, os balões ou nós alojam todos os conceitos que estão nos retângulos: desmineralização, cárie, dentina, dureza... . As linhas rel acionam os conceitos entre si , como: proteção e saúde bucal; tecido mineralizado e dureza; esmalte e prismas. As proposições podem ser visualisadas quando encontramos as palavras de ligação: proteção ‘per- mite’ saúde bucal ; cárie ‘lembra’ açúcar; esmalte 'sofre' desmineralização. A relação dente - dentina caracteriza uma relação cruzada, uma vez que esses dois conceitos estão dispostos graficamente em níveis diferentes.

Novak \& Gowin (1984) desenvolveram os mapas conceituais por meio de pesquisas sobre aprendizagem significativa de conceitos científicos utilizando material audiovisual. Para cada domínio apresentado no material, eles buscavam determinar o que os alunos sabiam antes e depois do seu uso e como esse conhecimento modificou-se nos anos seguintes. Tendo como enfoque metodológico um modelo modificado das entrevistas clínicas de Piaget e baseados na teoria da assimilação de Ausubel, eles coletavam informações sobre o conhecimento dos alunos. A preocupação em desenvolver uma forma de representação das mudanças ocorridas na estrutura cognitiva dos alunos levou-os, após vários anos de estudo, ao modelo de mapas conceituais.

A partir da concepção de tais mapas, várias técnicas foram desenvolvidas para a elaboração deles e análise e vários estudos avaliaram suas diferentes aplicações. Os mapas concei tuais podem ser integrados ao processo educativo de diferentes formas, como, por exemplo, ferramenta para o ensino, ferramenta para a avaliação curricular e ferramenta metacognitiva (Moreira \& Buchweitz, 1993).

Uma dada estrutura ou mapa é passível de análise relativa quanto ao número de conceitos, número de relações hierárquicas, distância semântica e coerência entre conceitos relatados. Algumas técnicas normalmente usadas priorizam uma ou mais características (Jonassen et al., 1993).

Existe uma série de modelos e técnicas de elaboração de mapas conceituais relatada na literatura. Após a análise desses modelos, selecionamos aquele que se apresentou mais compatível com o estudo (Jonassen et al., 1993).

- Entrevista com o especialista de conteúdo

Em razão da natureza do processo de avaliação por mapas conceituais, nos quais a especificidade de cada indivíduo e a estrutura cognitiva por ele representada são os principais parâmetros, a avaliação não pode se resumir a critérios de 'certo' ou 'errado'. Por isso, a análise do especialista de conteúdo é fundamental, pois é ele o único capaz de anal isar e interpretar a estrutura cognitiva representada pelo aluno num determinado domínio. Todas as considerações feitas pelo professor/ especialista de conteúdo 
sobre a avaliação e a pontuação dos mapas conceituais foram gravadas, transcritas e analisadas.

\section{Procedimentos para coleta de dados}

- Estudo-Piloto

Um estudo-pil oto foi realizado com a participação de alunos, docentes e funcionários do Laboratório de Tecnologias Cognitivas, com os seguintes objetivos: 1) possibilitar ao especialista de conteúdo/ professor praticar a estratégia de apresentação e o ensi no sobre elaboração de mapas conceituais previamente ao estudo definitivo e 2) decidir qual metodologia para a construção de mapas conceituais seria utilizada no estudo, oferecendo uma li stagem prévia dos conceitos para serem organizados pelos alunos ou deixando que os alunos gerassem os mapas com seus próprios conceitos.

Após experimentar as duas modalidades para a construção dos mapas, decidiu-se pela segunda, para deixar que o conhecimento dos alunos fluísse espontaneamente na elaboração do mapa conceitual.

\section{- Estudo definitivo}

Na primeira aula do semestre, os alunos da disciplina de Odontopediatria foram apresentados pelo professor aos conceitos e ao modelo de mapas conceituais. As expl icações sobre os mapas constaram de conceituação, principais elementos, pressupostos educativos associados à sua criação e estratégias para construção, incluindo a elaboração pelo professor, em sala de aula, de um exemplo de mapa sobre o tópico Saúde Oral.

Os alunos receberam o material para a elaboração do mapa conceitual: papel, lápis e borracha. Foram, então, solicitados a fazer os mapas, baseando-se nos seus conhecimentos relacionados ao conceito de esmal te dentário.

\section{Análise e resultados}

Análise quantitativa

Os mapas conceituais de cada aluno foram pontuados pel o especialista de conteúdo, seguindo as especificações de Novak \& Gowin (1984). O escore de um mapa conceitual foi calculado por meio dos seguintes indicadores e critérios: proposições/ligações válidas (pl): um ponto cada proposição; relações hierárquicas com níveis válidos (rh): cinco pontos cada nível; conexões cruzadas válidas e significativas (cs): dez pontos cada conexão; exemplos válidos (ev): um ponto cada. O somatório dos pontos obtidos pelo aluno corresponde ao escore no mapa conceitual.

Os pontos obtidos pel os alunos nos mapas conceituais, utilizando os critérios de pontuação de Novak, estão sumarizados na Tabela 1.

Os resultados quantitativos apontaram para uma estrutura de conhecimento elaborada com poucas ligações entre conceitos na forma de proposições ou princípios básicos, ou seja, na explicação e síntese das hierarquias apontadas. De uma maneira geral, o grupo, como podemos verificar na Tabela 1, foi capaz de hierarquizar validamente os conceitos, variando a organização de seus mapas de um a nove níveis, sendo a média de 20,5 e mediana de quatro níveis ou 20 pontos. Os mapas conceituais foram diversificados em relação ao número de ligações válidas/ proposições entre conceitos, variando de uma a 29 proposi ções corretas com média de 9,9 e mediana 9. O grupo demonstrou baixíssimo conhecimento das interconexões entre conceitos, nível mais elaborado de conhecimento sobre um domínio; 36 dos 38 alunos não representaram qual quer interconexão e dois representaram uma única interligação (por mapa) entre dois ou mais conceitos em níveis diferenciados na hierarquia, formando novas proposições.

A interpretação do mapa conceitual e desse processo de pontuação é de relativa dificuldade e carrega um certo nível de arbitrariedade (como outros métodos de avaliação) e, como é colocado pelo próprio Novak (Novak \& Gowin, 1984), sua função é satisfazer às necessidades de nosso sistema escolar, muito mais baseado em números e outras formas de escores para avaliar a aprendizagem. Mesmo defendendo que a proposta de pontuação dos mapas conceituais é válida e está an corada nas teorias de

Tabela 1

Síntese dos pontos obtidos nos mapas conceituais elaborados pelos alunos por fator, de acordo com a classificação de N ovak ( $\mathrm{N}=38$ ).

\begin{tabular}{lrccc}
\hline Fator & Média & D.P. & Mínimo & Máximo \\
\hline Hierarquias (peso 5) & 20,5 & 9,5 & 5 & 45 \\
Ligações/Proposições (peso 1) & 9,9 & 5,8 & 1 & 29 \\
Conceitos Cruzados (peso 10) & 0,5 & 2,3 & 0 & 10 \\
Exemplos (peso 1) & 0,2 & 0,8 & 0 & 4 \\
Total (somatório de pontos) & 31,2 & 14,8 & 6 & 68 \\
\hline
\end{tabular}


aprendizagem significativa, o autor destaca que a característica fundamental do mapa conceitual não é atribuir notas ou conceitos aos alunos, mas avaliar sua estrutura cognitiva e as mudanças qualitativas ocorridas em decorrência do processo de instrução, isto é, a evolução do conhecimento dos alunos.

Um aspecto que pode ter influenciado os baixos escores dos alunos nos diferentes fatores da teoria da aprendizagem significativa de Ausubel é a falta de experiência na elaboração de mapas conceituais, o que reforçou a necessidade de expandir as análises para uma abordagem qualitativa e mais hermenêutica das estruturas de conhecimento registradas pelos alunos de Odontopediatria, no segundo encontro do semestre.

\section{Análise qualitativa}

Para realizar a análise qualitativa, o especialista descreveu e analisou os mapas conceituais de cada aluno, na presença de três membros da equipe de pesquisa. Os depoimentos foram gravados, transcritos e posteriormente analisados. Além da avaliação dos mapas, o especialista/ professor respondeu perguntas sobre a experiência de trabalhar com essa estratégia de avaliação e sobre a receptividade dos alunos em relação ao mapa.

Na aval iação individual dos alunos, o professor analisou cada mapa, apontando suas características. A análise qualitativa seguiu, inicialmente, os mesmos conceitos da metodologia proposta por Novak \& Gowin (1984), que analisa os elementos constituintes da teoria da aprendizagem significativa de Ausubel, representados na estrutura de um mapa conceitual. São eles: hierarquias, proposições e conexões cruzadas entre conceitos e, também, exemplos de conceitos, como já foi descrito anteriormente. No entanto, o professor/especialista não se prendeu única e exclusivamente a estes, na medida em que a análise quantitativa já havia possibilitado um quadro geral dos alunos em relação a esses fatores.

Ao analisar os mapas, o especialista apontou diversos aspectos apresentados pelos alunos, relativos à forma de organização e de expressão de conceitos relacionados à temática esmalte. Tais observações foram, então, categorizadas e analisadas quanto à sua pertinência para a compreensão sobre a estrutura do conhecimento dos alunos de sétimo período do curso de graduação de Odontologia na Universidade Federal do Rio de Janeiro.

I nicial mente foram geradas cinco categorias básicas, que foram então definidas e rea- valiadas com o especialista a partir de uma nova leitura dos mapas. Quando todas as categorias ficaram definidas, as diferentes características a elas atribuídas foram identificadas de acordo com as ocorrências nos mapas conceituais dos alunos.

As categorias definidas e os resultados obtidos estão descritos a seguir.

\section{1) Dificuldades na construção do mapa}

Por relacionar-se a problemas que dificultaram a avaliação dos mapas conceituais pelo especialista, segundo o qual essa situação se deve à dificuldade dos alunos para construírem seus mapas, esta categoria se tornou importante porque, em alguns casos, levou à necessidade de interpretação das intenções dos alunos (ou seja, do raciocínio que embasava a estrutura representada). Muito mais do que uma função classificatória/conceitual do conhecimento dos alunos, teve o papel de monitoramento ou checagem das conclusões durante a análise, isto é, qual quer outra classificação era reavaliada inicialmente considerando-se esta categoria antes de buscar suas características fundamentais.

Dos 38 al unos que participaram da atividade de elaboração dos mapas conceituais, 11 (29\%) o fizeram sem deixar dúvidas quanto à compreensão de suas técnicas de elaboração. Os alu nos restantes representaram tipos e níveis de distanciamento diferenciados dos mapas: dois alunos (5\%) não construíram mapas, do ponto de vista gráfico, e apresentaram sentenças; oito (21\%) apresentaram longas listas de conceitos encadeados seqüencialmente, sendo seis em formato horizontal e dois em vertical; sete (19\%), apesar de terem elaborado diagramas de árvore, não deixaram, nem pelo esquema, nem pelo texto, pistas sobre a interrelação pretendida entre os conceitos e, finalmente, dez (26\%) alunos combinaram seus mapas ora explicitando proposições, ora não, porém deixando margens para a devida interpretação (Figura 1).

Podemos identificar, então, uma substantiva dificuldade na elaboração de mapas conceituais, que poderia ser atribuída à falta de experiência em relação não apenas à sua forma diagramática, mas também à natureza do raciocínio por conceitos e suas inter-relações. Isso porque, de uma maneira geral, a cultura institucional não deve privilegiar esse tipo de avaliação (Novak \& Gowin, 1984; N ovak, 1998; Jonassen et al., 1993). 
Dificuldade na construção do mapa: o aluno elaborou uma lista de palavras encadeadas não necessariamente relacionadas e sem diferenciação hierárquica (Aluno oo 29).

$$
\begin{aligned}
& \text { Gsmalt } \rightarrow \text { eśrie } \rightarrow \text { prisimos } \rightarrow \text { dentino } \rightarrow \text { polpo } \rightarrow \text { amelo- } \\
& \text { blostas } \rightarrow \text { Lente } \rightarrow \text { transhuaidez } \rightarrow \text { atagun ácisto } \rightarrow \\
& \text { adesino } \rightarrow \text { esroa do derot } \rightarrow \text { mancha hranca otinio } \rightarrow
\end{aligned}
$$

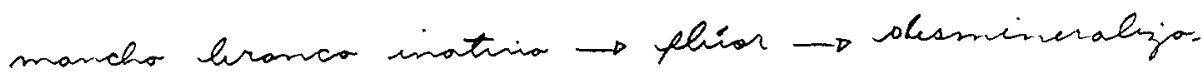

$$
\begin{aligned}
& \begin{array}{l}
\text { ear } \rightarrow \text { remineralizaça } \rightarrow \text { placo hacteriaino } \rightarrow \text { sucas } \\
\text { pigmentodor } \rightarrow \text { hio } \rightarrow \text { rugoso } \rightarrow \text { hipoplosio. }
\end{array}
\end{aligned}
$$

\section{2) Organização do pensamento}

Esta categoria identifica as diversas organizações/ estruturas de pensamento sobre a temática do esmalte representadas pelos alunos. $\mathrm{Na}$ verdade, ela baseia-se no fundamento principal da teoria de Ausubel: quando há conhecimento significativo, os con ceitos são organizados em estruturas hierárquicas, isto é, de forma subordinada a outros mais gerais. Para Ausubel et al. (1978), a aprendizagem significativa se dá pela diferenciação progressiva entre conceitos mais específicos e conceitos mais abrangentes já existentes, formando proposições que nada mais são que a explicitação da natureza da relação entre esses conceitos (por exemplo, o esmalte é composto por matéria inorgânica constituída de cristais e por matéria orgânica); posteriormente, vários conceitos específicos podem tender a se reorganizar e a se interligar, formando novos conceitos e proposições, tornando a estrutura do domínio cada vez mais refinada. A estrutura conceitual de um conhecedor ou de um profissional que passou por diversos estágios de aprendizagem sobre a temática do esmal te em diferentes disciplinas de seu curso de formação, e que necessita desses conhecimentos, deveria, a princípio, representar essa estrutura hierárquica, como estabelecida pela teoria.

Apenas dez alunos (26\%) apresentaram uma organização que seguiu uma estrutura hierárquica do conhecimento, seguindo a lógi ca do geral para o específico, segun do a teoria (Figura 2). Em geral, predominou a relação contrá- ria, que vai do específico para o geral, ou seja, dos objetos e dos fatos concretos aos conceitos mais gerais, ocorrendo em 17 (45\%) dos casos (Figura 3). Um grupo de oito alunos (21\%) apresentou uma estrutura mista e três alunos (8\%) não puderam ser classificados, por causa da desorganização e do pequeno número de conceitos apresentados.

Muito embora esses resultados possam indicar também dificuldades na elaboração do mapa, a tendência a esse estilo de organização pode ser reveladora do modelo de conhecimento mais comum entre os estudantes de Odontologia. Segundo Pozo (1998), Ausubel et al. (1978) consideram que não apenas a aprendizagem de conceitos se dá do geral para o mais específico, "seguindo uma via descendente se melhanteà definida por Vigotsky em re ação à aprendizagem de conceitos científicos" (Pozo, 1998:219), mas também que, embora comportando os mesmos conceitos, essas estruturas são inteiramente diferentes. Para Pozo, é exatamente essa característica que diferencia a aprendizagem condutivista/associacionista, que considera que o conhecimento se consolida com o somatório de uma série de conceitos inferiores, da aprendizagem construtivista ou por reestruturação, que pressupõe uma lógica própria que vai possibilitando, com seu refinamento, alcançar cada vez mais estruturas com as características fundamentais e os elementos essenciais de um determinado domínio.

As idéias de Vigotsky (1996) sobre a formação de conceitos científicos e de pseudoconceitos parecem fundamentais para uma me- 
O rganização do pensamento: do geral para o específico. O rganização hierárquica significativa dos conceitos mais abrangentes para os mais específicos (Aluno oo 30).

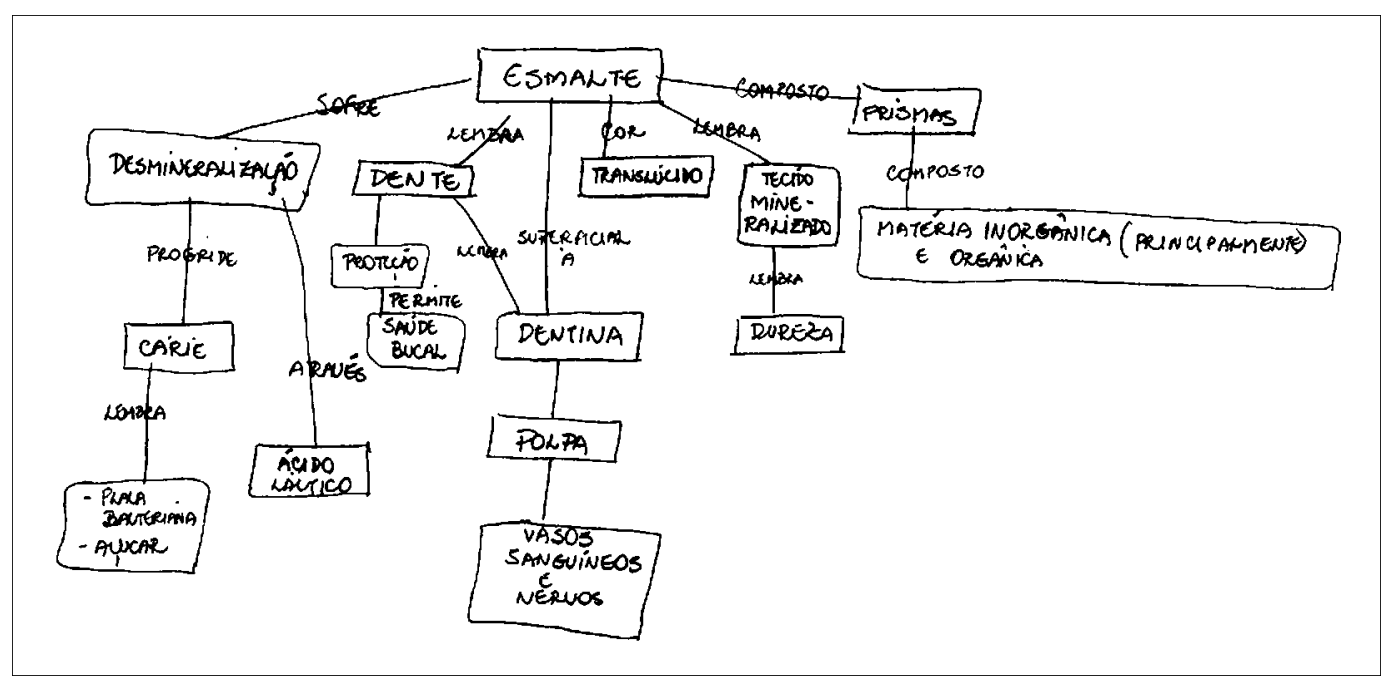

Figura 3

O rganização do pensamento: do específico para o geral. O rganização hierárquica significativa dos conceitos mais específicos para os mais gerais (Aluno № 14).

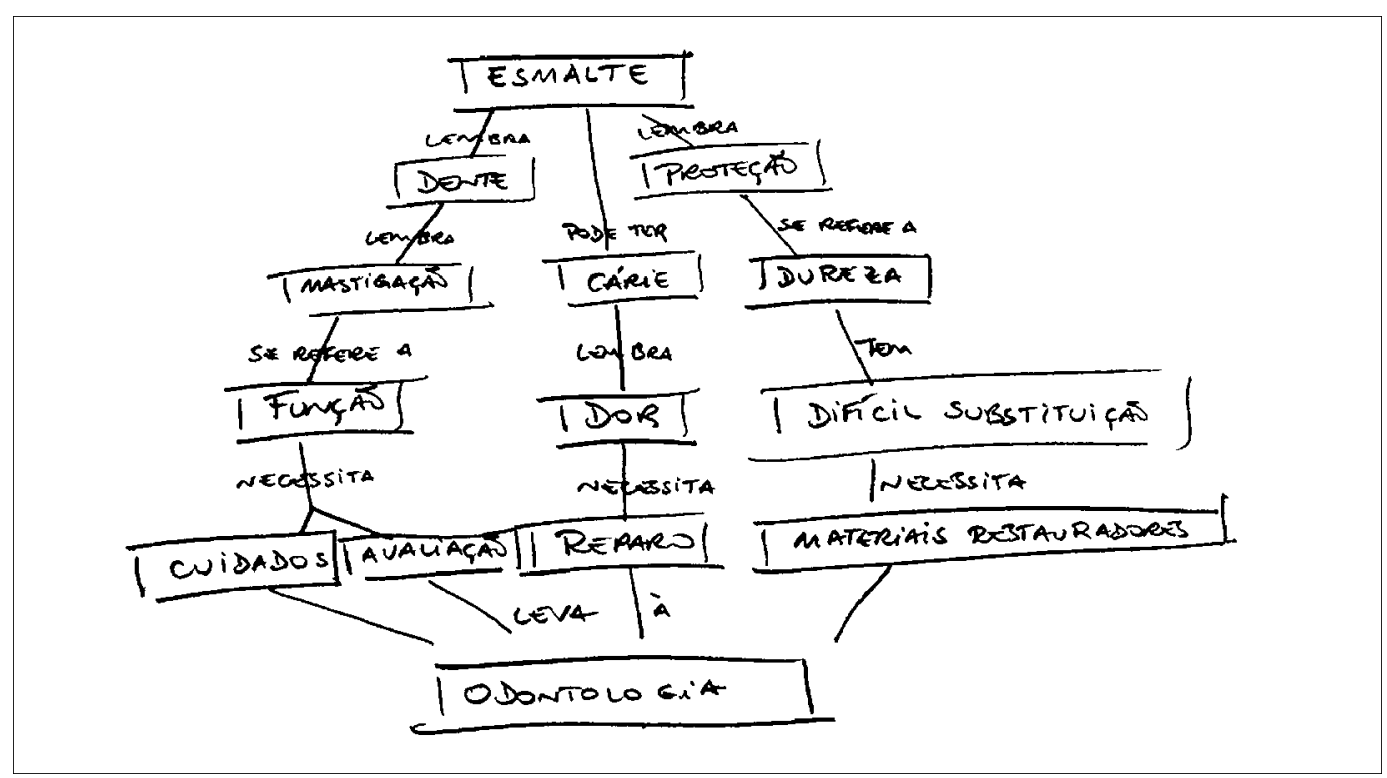


Ihor compreensão das estruturas conceituais apresentadas pelos al unos. Para Vigotsky (Pozo, 1998), os conceitos verdadeiros são os científicos, adquiridos por meio de processos instrucionais; o desenvolvimento de conceitos espontâneos ou pseudoconceitos se dá de forma ascendente, do concreto para o abstrato, ao passo que os conceitos científicos desenvolvem-se de forma descendente, numa pirâmide de conceitos, ou seja, por caminhos diametralmente opostos.

“Assim, os conceitos espontâneos são adquiridos edefini dos a partir dos objetos, por sua re ferência, enquanto os concei tos científicos são adqui ri dos sempre por relação hierárquica com outros concei tos, por seu senti do. Isto faz com que nos conceitos científicos chegue a captar-se a 'essência' do conceito, possível mediante a anál i se consciente de suas relações com outros conceitos" (Pozo, 1998:203).

Os resultados verificados nos mapas conceituais dos alunos podem ser decorrentes de um processo educativo que não estimula e muito menos cobra a tomada de consciência dos fundamentos da matéria estudada e, portanto, de sua base científica. Isso pode estar relacionado tanto à cultura e representação feita sobre o papel e função social desse profissional, como às estratégias de ensino-aprendizagem utilizadas no processo educacional em Odontologia.

\section{3) Erros de conceituação}

Os conceitos espontâneos ou pseudoconceitos são normalmente diferentes dos conceitos científicos por natureza e pressupostos, como já foi observado anteriormente. Por estarem ligados mais aos elementos concretos, ou seja, às características dos obj etos e menos ao sentido de suas relações, as concepções espontâneas não incorporam a consciência reflexiva em relação à organização hierárquica dos conceitos, o que impede uma reconstrução contínua do conhecimento baseado na compreensão de seus fundamentos essenciais. Isso pode fazer com que as concepções espontâneas manifestem-se e tornem-se relativamente estáveis como concepções errôneas, neste caso próprias de pessoas leigas, cuja vivência no campo da Odontologia diferencia-se da vivência do especialista.

Nos mapas conceituais dos alunos de Odontologia foram encontrados quatro casos (11\%) em que os alunos conceituaram cárie como uma lesão que acomete o dente, em vez de uma doença que causa lesões nos dentes (a expressão “este sujeito tem muitas cáries” é errônea, já que cárie refere-se à doença e não às lesões causadas por ela). Um grupo de sete alunos (18\%) atribuiu cor branca ao esmalte (a idéia de dentes brancos é muito veiculada na mídia), quando este é transparente (Figura 4).

Muito embora não tenham sido representativas da turma, as concepções errôn eas devem ser trabalhadas no grupo, na medida em que elas podem interferir nas decisões clínicas e nas práticas dos futuros profissionais. Além disso, essa questão é mais grave ainda quando levamos em conta que os conceitos centrais de uma pessoa em um determinado domínio são os veículos por meio dos quais uma gama de fenômenos são compreendidos.

\section{4) Abrangência da temática}

Esta categoria tem relação com o nível de desenvolvimento e elaboração dos mapas conceituais sobre a temática do esmal te. Tendo como objetivo a construção de uma rede de conhecimentos baseados no conceito de esmalte, esperava-se que o aluno com uma visão científica sólida fosse capaz de relacionar aspectos específicos e aprofundar esta temática de forma abrangente.

Dos 38 al unos que participaram da atividade, 21 (55\%) desenvolveram seus mapas extrapolando o foco da temática do esmalte, sendo, portanto, mais superficiais e pouco abrangentes no tema propriamente dito; 16 (42\%) con-

Figura 4

Erros de conceituação: ausência de associação do esmalte com a cárie; concepção errônea do esmalte como sendo branco e posterior contradição ao afirmar que é translúcido. (Aluno oo 11)

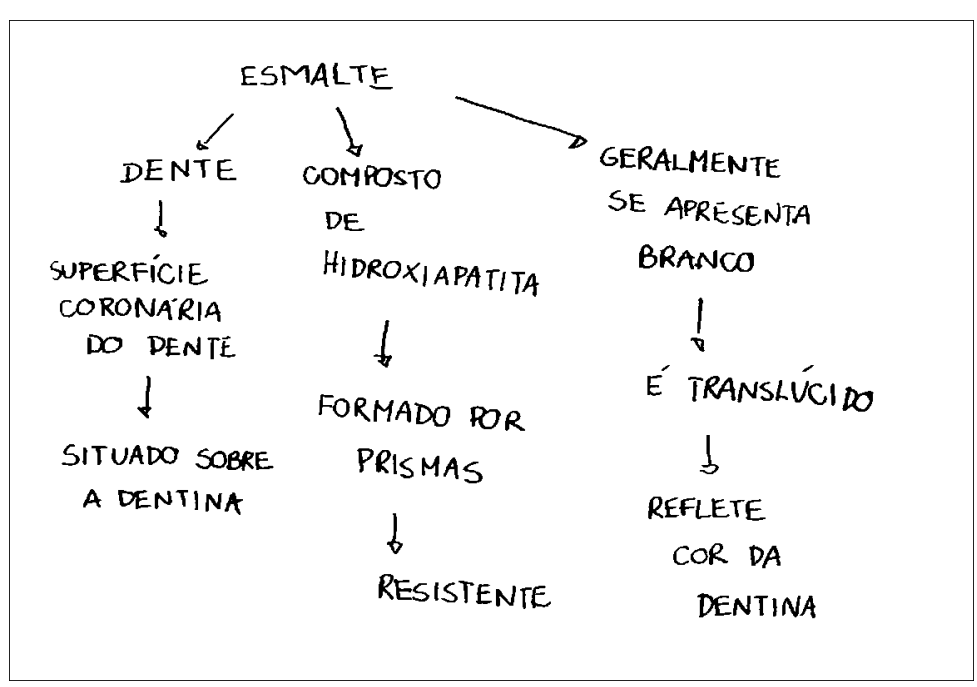


centraram-se em conceitos relacionados ao esmal te e um aluno (3\%) fugiu totalmente ao tema. É interessante notar que há uma relação entre a categoria organização do conhecimento e a abrangência da temática: dos 21 alunos que se desviaram da temática do esmalte, 19 (90\%) coincidentemente não desenvolveram os mapas conceituais seguindo o modelo de subordinação de conceitos (Figura 5).

Na concepção de Ausubel et al. (1978), os conceitos de hierarquia e con exão cruzada são elementos dinâmicos, e um determinado conceito abrangente pode ser específico em outro contexto, e assim sucessivamente. Por isso, ao propor a construção de um mapa conceitual sobre esmalte, esperava-se um maior aprofundamento em suas características, elementos, estrutura, fi si ologia e interconexões com outros aspectos da composição do dente e de seu estado físico.

Os resultados obtidos nesta categoria corroboram a teoria de Vigotsky (Pozo, 1998), uma vez que revelam que aquel es que não foram capazes de trabalhar com o tema esmalte como categoria supra-ordinária provavelmente não estão familiarizados com os princípios fundamentais desse fenômeno e, portanto, não detêm conhecimento científico aprofundado (elementos essenciais do domínio) sobre o assunto.
5) Representações sobre a prática profissional e influência do currículo

A natureza desta última categoria está mais relacionada a aspectos sócio-culturais e a valores dados a determinados aspectos da prática profissional, que terminam por influenciar o currículo e o conhecimento dos alunos. Por exemplo, quando um conceito é trabalhado, geralmente é colocado em contextos considerados mais relevantes pelos al unos. Esses valores estão associados às representações que os alunos fazem de suas atividades profissionais, as quais provavel mente motivaram-nos a buscar a carreira em questão, aos conceitos e modelos sobre a prática do dentista que permeiam a grade curricular e ao modelo preconizado pelos docentes.

Segundo a análise do professor especialista, apareceram al gumas tendências mais relacionadas à temática, e a valorização do conhecimento técnico-curativo foi identificada em 19 alunos (50\%), que tenderam a relacionar esmal te com técnicas reparadoras de lesões e outros acometimentos dentários (prótese), seja no sentido de aliviar a dor dos pacientes (anestesia, dormência, dor), seja, principalmente, no sentido estético: sorriso, beleza, satisfação pessoal etc. (Figura 6). Note-se que, em alguns

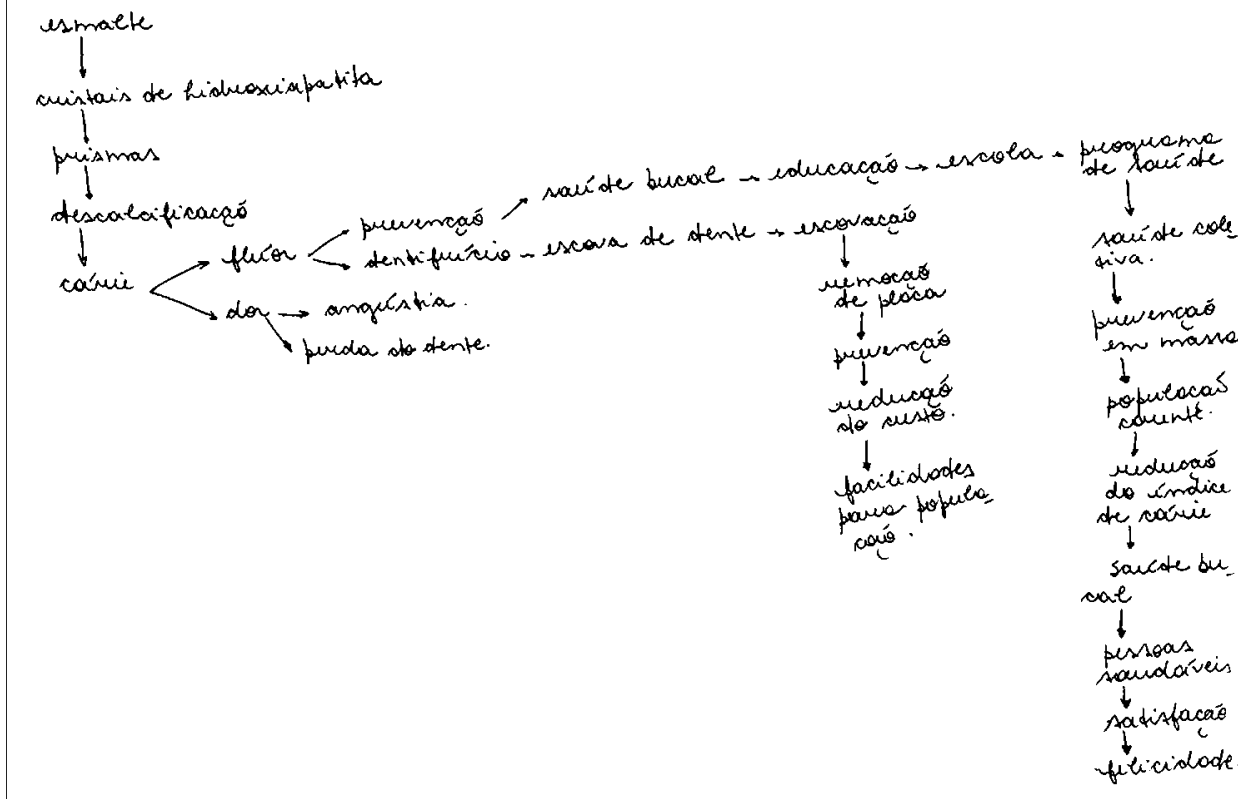


casos, os alunos mencionaram não apenas os procedimentos e técnicas, mas também os instrumentos e materiais disponíveis para a intervenção reparadora (consultório, instrumental, metal, broca, resina etc).

Nove alunos (24\%) enfatizaram os conhecimentos mais básicos, ou seja, histológicos, em seus mapas (estrutura, características e elementos), indicando uma maior preocupação com conceitos fundamentais sobre o esmalte. Estes alun os tenderam a não relacionar aspectos das ciências básicas, nem com a clínica operatória, nem com a prevenção. Alguns alunos ( $n=5,13 \%$ ) relacionaram conhecimentos técnicos com aspectos preventivos, demonstrando a aplicação de conceitos à prática da prevenção de doenças e promoção da saúde (Figura 7). Três (8\%) segui ram uma lógica de estruturação que, partindo do conceitos básicos, direcionou-se para a visão técnica. Quanto aos dois alunos restantes, um enfatizou apenas aspectos relativos à prevenção e outro fugiu totalmente à temática, não tendo sido possível analisá-lo.

\section{Discussão}

Com base na análise da experiência e dos depoimentos do especialista/ professor no que se refere a esse método de avaliação do conhecimento dos alunos, pode-se concluir que se trata de um modelo muito mais complexo e trabalhoso que os métodos tradicionais, porém é bem mais eficaz para a análise aprofundada sobre o conhecimento revelado pelo aluno, inclusive para um diagnóstico das concepções errôneas (misconceptions) e de seus determinantes do ponto de vista da conformação da estrutura cognitiva. Conforme constatou o professor, tais métodos não são compatíveis com modelos de ensino correntes e nem com a cultura pedagógica da universidade, compartilhada pelos próprios alunos, que priorizam a transmissão e memorização de informações em suas atividades.

O professor apontou que os alunos tiveram dificuldades em executar o mapa conceitual, muito embora tivessem sido receptivos para participar de sua elaboração e tivessem, de uma maneira geral, evidenciado uma compreensão geral de seus elementos e princípios. Ser uma primeira experiência dos alunos com o uso de mapas conceituais e estar distanciado das práticas 'oficiais' de avaliação podem constituir al gumas das causas associadas aos problemas encontrados e das características conceituais apresentadas pelos al unos. No entan- to, a forma consistente com que esses proble mas ocorreram nos possibilita tecer considerações sobre a estrutura de conhecimento revelada pelos alunos sobre a temática do esmalte e as categorias construídas tendo como base sua análise, bem como refletir sobre suas implicações para o processo de formação do dentista.

Pozo (1996) anali sou três abordagens relacionadas à tradição construtivista da educação científica: a teoria piagetiana das operações formais, o enfoque dos conhecimentos prévios ou concepções alternativas e o enfoque das teorias implícitas. O enfoque dos conhecimentos prévios ou concepções alternativas na formação de conceitos científicos oferece um referencial importante para compreendermos os resultados obtidos no presente estudo. Segundo Pozo, esse enfoque é caracterizado por “construções pessoais, relativamente incoerentes, resistentes à mudança, de caráter implícito, compartilhadas em culturas e contextos..." (Pozo, 1996:119). O autor caracteriza essas concepções em três tipos, levemente diferenciados de acordo com sua origem:

As concepções espontâneas são de origem sensorial, nascendo da relação do indivíduo com seu mundo natural; são teorias construídas pelo indivíduo no interior de suas atividades cotidianas.

Figura 6

Valorização do conhecimento técnico (Aluno no 20).

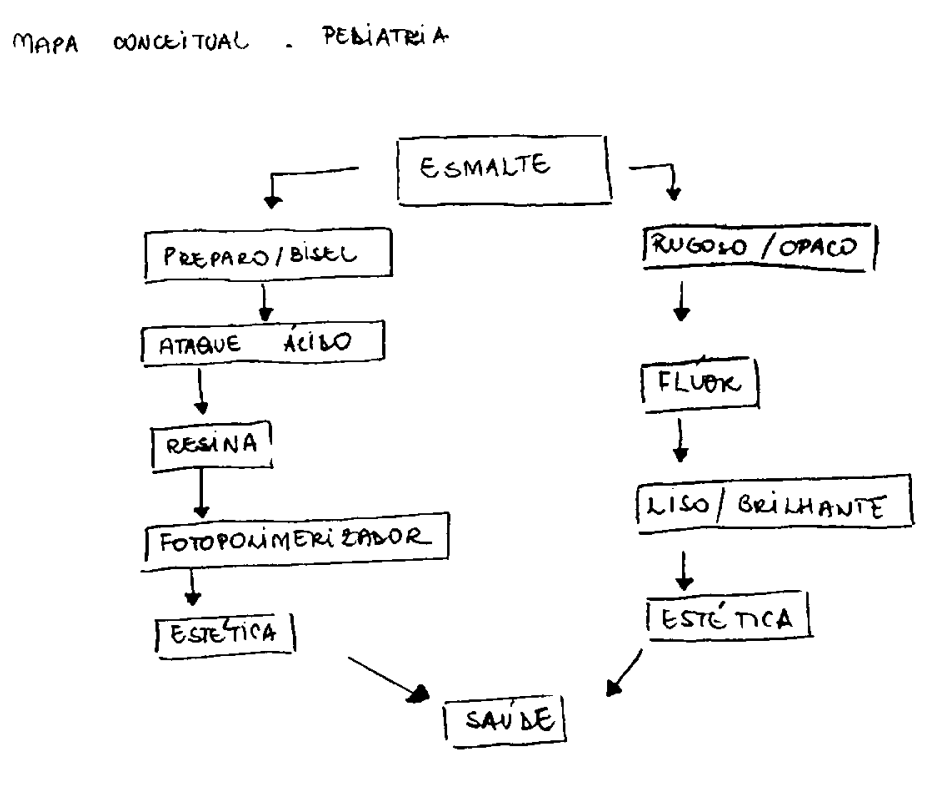




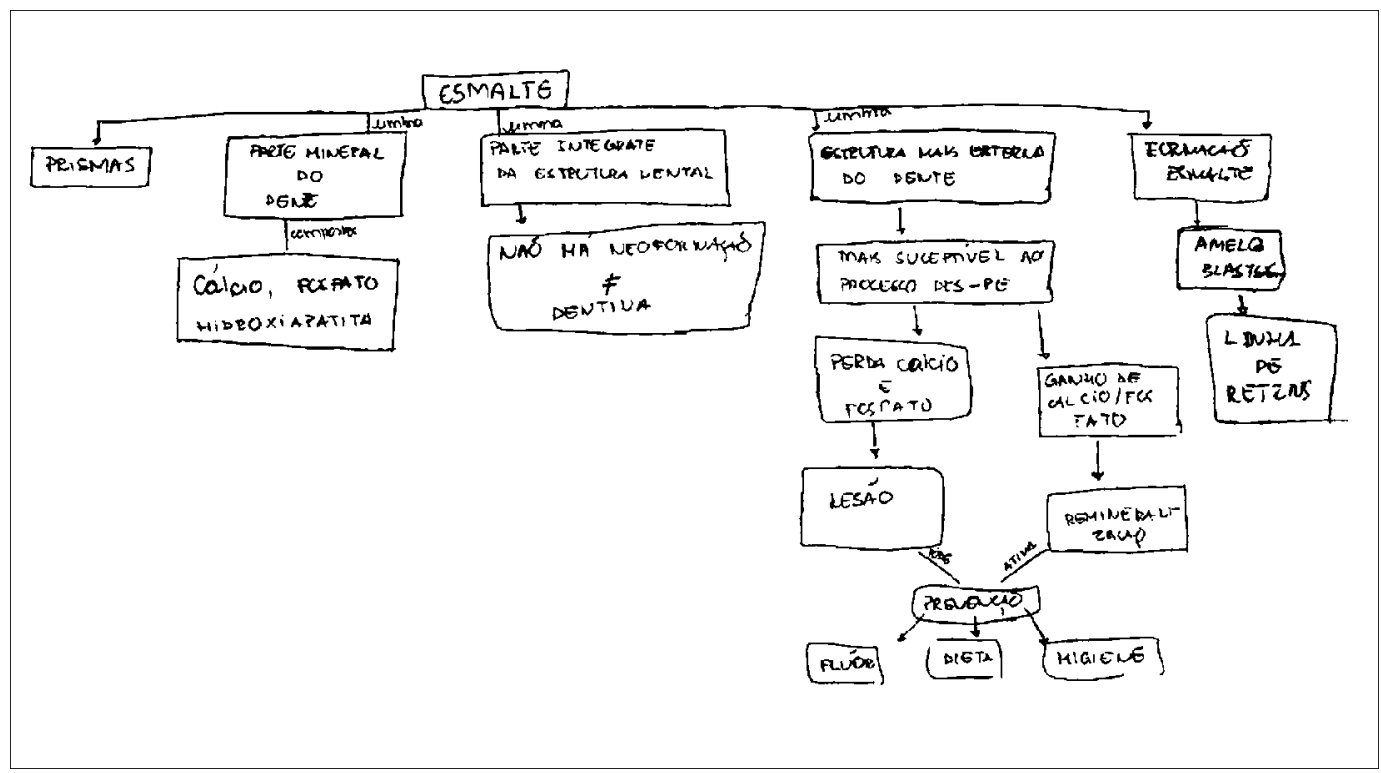

As concepções sociais são de origem cultural, ou seja, nascem do estudante e de seu meio social e constituem valores, crenças e representações que influenciam sua compreensão do mundo, sua aprendizagem e seus interesses.

As concepções escolares são aquelas que nascem das inter-relações e mediações no âmbito do espaço escolar, por meio de relações entre membros deste sistema e dos materiais de ensino, ou amplificadores culturais (Mortimer \& Carval ho, 1996), como livros, apostilas, vídeos, softwares educativos etc.

Do ponto de vista de sua estrutura conceitual, a categoria Organização do Pensamento é caracterizada por um grupo significativo de alunos que representou seu mapa conceitual colocando o esmalte como categoria específica e desenvolvendo o conteúdo do mapa do nível específico para o mais geral, ou seja, enfatizando muito mais os elementos e objetos do que a inter-rel ação entre eles. Da mesma forma, a categoria Abrangência da Temática, intrinsecamente relacionada à primeira, apontou para um conhecimento restrito sobre esmalte, que levou os alunos, de um modo geral, a serem superficiais no desenvolvimento conceitual sobre esmalte e a extrapolarem o tema. Estas características indicam uma formação debilitada dos conceitos científicos dos alunos, segundo as teorias de Ausubel et al. (1978) e de Vigotsky (1996).
Quanto aos Erros de Conceituação, apesar de terem ocorrido em poucos casos, devem ser levados em consideração, na medida em que indicam que muitas das teorias implícitas (Pozo, 1996) dos alunos não foram capazes de sofrer transformações a partir das experiências de ensino vivenciadas e estas, muito provavelmente, não levam em conta os conhecimentos prévios dos alunos, nem contribuem para a formação de conceitos científicos.

A outra categoria, Representações sobre a Prática Profissional e Influência do Currículo, está relacionada com valores e princípios em relação à prática profissional, orientando a formação de atitudes e modelos de posturas, bem como o foco das atividades acadêmicas no que diz respeito à abordagem curricular e às atividades de ensino-aprendizagem. É muito difícil definir a origem desses valores e é provável que grande parte seja construída pela sociedade, por meio de suas interações sócio-econômicas e culturais em geral, e especificamente pela comunidade científica no âmbito da universidade. Provavelmente, os estudantes que escoIhem exercer a profissão de dentista têm suas próprias concepções sobre a prática odontológica, as quais nascem de suas experiências pessoais (por exemplo, como paciente) e da própria cultura social. Essas concepções devem, inclusive, influenciar a própria preferência profissional. 
De qualquer forma, o importante é considerar que todas as categorias derivadas deste estudo estão intrinsecamente relacionadas, influencian do-se mutuamente, e que a comunidade acadêmica necessita repensar o processo de formação e a inserção do profissional no ambiente de trabalho na área da saúde, possibilitando a internalização e a aprendizagem de conceitos de forma integrada. Assim, contribuirá para a transformação de suas práticas e, portanto, para um melhor atendimento da população na área de saúde oral. Para isso, é fundamental não apenas conhecer essas concepções profundamente, mas levar em conta os resultados aqui discutidos no planejamento das atividades curriculares.

\section{Conclusão}

O objetivo inicial deste trabalho foi apreender a estrutura de conhecimento de alunos de graduação em Odontologia sobre a temática do esmalte. Esta temática é de fundamental importância para a compreensão da saúde oral, na medida em que oferece conceitos científicos importantes e fundamentais para o exercício da prática clínica e preventiva dos futuros profissionais.

Botero (1990) apontou três aspectos que caracterizam a formação do profissional de

\section{Agradecimentos}

Ao Departamento de Odontopediatria e Ortodontia da Facul dade de Odontologia da Universidade Federal do Rio de Janeiro, por permitir que essa experiência fosse realizada com os alunos da disciplina de Odontopediatria I. Ao CNPq (Conselho Nacional de Desenvolvimento Científico e Tecnológico) eà FAPERJ (Fundação de Amparo à Pesquisa do Estado do Rio de Janeiro), pelo apoio à execução do projeto.
Odontologia: a) não existe um equilíbrio entre as abordagens, predominan do as disciplinas técnico-restauradoras sobre as demais; b) existe muito pouca correlação entre as ciências básicas e as clínicas e c) não desperta no estudante $o$ interesse pelas disciplinas humanitárias. A análise qual itativa revel ou valores e concepções dos estudantes sobre o conceito da prática odontológica, influenciados por aspectos sociais e pelas características curriculares: o papel do dentista é visto como eminentemente curativo e corretivo (intervencionista) de problemas que afligem o paciente, como dor de dente e aspectos estéticos (prótese). Em poucos casos os alunos demonstraram posturas educativas e/ ou preventivas ou a compreensão ampla dos fenômenos determinantes da formação e dos problemas dentários.

Isso é um forte indicativo de que a formação do profissional em Odontologia deve ser repensada. Em outras pal avras, deve afastar-se do modelo de profissional que entende o seu paciente como uma unidade dentária, passando a compreendê-lo como um ser humano integral. Para isso, é necessário repensar o processo ensino-aprendizagem valendo-se das concepções dos alunos, para que estes possam fazer as necessárias relações e internalizá-las, construindo novos conceitos.

\section{Referências}

ABEM (Associação Brasileira de Educação Médica), 1983. Integração docente-assistencial. Série Documentos, 6:88.

AUSUBEL, D. P.; NOVAK, J. D. \& HANESIAN, H., 1978. Educational Psychology: A CognitiveView. New York: Holt, Rinehart, \& Winston.

BEDNAR, A. K.; CUNNINGHAM, D.; DUFFY, T. M. \& PERRY, J. D., 1992. Theory into practice: How do we link? In: Constructivism and the Technology of Instruction: A Conversation (T. M. Duffy \& D. H. Jonassen, eds.), pp. 17-34, Hillsdale: Lawrence Erlbaum.

BOTERO, A. A., 1990. La Enseñanza dela Odontología. Medellín: Editorial Universidad de Antioquia.

CUNNINGHAM, D. J.; DUFFY, T. M. \& KNUTH, R. A., 1993. The textbook of the future. In: Hypertext: $A$ Psycological Perspective(C. McKnight, A. Dillon \& J. Richardson, eds.), pp. 19-49, New York: Ellis Horwood. 
DUFFY, T. M. \& JONASSEN, D. H., 1993. Constructivism: New implications for instructional technology. In: Constructivism and the Technology of Instruction: A Conversation (T. M. Duffy \& D. H. Jonassen, eds.), pp. 1-16, Hillsdale: Lawrence Erbaum.

JATENE, A. D., 1987. Com a palavra o Sr. Ministro. Boletim da Associação Brasileira de Educação Médica, 19:4.

JONASSEN, D. H., 1996. Computers in the Classroom: Mindtools for Critical Thinking. Englewood Cliffs: Prentice-Hall Inc.

JONASSEN, D. H.; BEISSNER, K. \& YACCI, M., 1993a. Structural Knowledge: Techniques for Representing, Conveying, and Acquiring Structural Knowledge. Hillsdal e: Lawrence Erlbaum.

JONASSEN, D. H. \& GRABOWSKY, B. I., 1993b. Handbook of Individual Differences, Learning and Instruction. Hillsdale: Lawrence Erlbaum.

KOM MERS, P. A. M.; GRABINGER, S. \& DUNLAP, J. C., 1996. Hypermedia Learning Environments: Instructional Design and Integration. Mawah: Lawrence Erlbaum.

MOREIRA, M. M. \& BUCHWEITZ, B., 1993. Novas estratégias de ensino eaprendizagem. Lisboa: Plátano Edições Técnicas.
MORTIMER, E. F. \& CARVALHO, A. M. P., 1996. Referenciais teóricos para análise do processo de ensino de Ciências. Cadernos dePesquisa, 96:5-14.

NOVAK, J. D. \& GOWIN, D., 1984. Learning How to Learn. Cambridge: Cambridge University Press.

NOVAK, J. D., 1998. Learning, Creating, and Using Knowledge. Mawah: Lawrence Erlbaum.

STRUCHINER, M. \& VIEIRA, A. R., 1998. Esmalte: A Porta de Entrada do Dente. Software educativo. Rio de Janeiro: Laboratório de Tecnologias Cognitivas, Núcleo de Tecnologia Educacional para a Saúde, Universidade Federal do Rio de Janeiro.

POZO, J. I., 1996. La psi cología cognitiva y la educación científica. Investigações em Ensino de Ciências, 1:110-131.

POZO, J. I., 1998. Teorias Cognitivas da Aprendizagem. Porto Alegre: Artes Médicas.

SILVA, G. R., 1987. Uma retrospectiva da educação médica no Brasil. Revista Brasileira de Educação Médica, 11:73-140.

VIGOTSKY, L. S., 1996. Formação Social da Mente. São Paulo: Martins Fontes.

WILSON, B. G., 1996. What is constructivist learning environment? In: Constructivist Learning Environments: Case Studies in Instructional Design. (B. G. Wilson, ed.), pp. 3-8, Englewood Cliffs: Educational Technology Publications. 